\title{
Reconstruction Techniques for Tissue Defects Formed after Preauricular Sinus Excision
}

\author{
Myung Joon Lee, Ho Jik Yang, Jong Hwan Kim \\ Department of Plastic and Reconstructive Surgery, Eulji University Hospital, Eulji University School of Medicine, Daejeon, Korea
}

Background Preauricular sinuses are congenital abnormalities caused by a failure of fusion of the primitive tubercles from which the pinna is formed. When persistent or recurring inflammation occurs, surgical excision of the infected tissue should be considered. Preauricular defects inevitably occur as a result of excisions and are often difficult to resolve with a simple suture; a more effective reconstruction technique is required for treating these defects.

Methods After total excision of a preauricular sinus, the defect was closed by a plastic surgeon. Based on the depth of the defect and the degree of tension when apposing the wound margins, the surgeon determined whether to use primary closure or a posterior auricular flap.

Results A total of 28 cases were examined. In 5 cases, including 2 reoperations for dehiscence after primary repair, reconstruction was performed using posterior auricular transposition flaps. In 16 cases of primary closure, the defects were closed using simple sutures, and in 7 cases, closure was performed after wide undermining.

Conclusions If a preauricular defect is limited to the subcutaneous layer and the margins can be easily approximated, primary closure by only simple suturing may be used to perform the repair. If the defect is deep enough to expose the perichondrium or if there is tension when apposing the wound margins, wide undermining should be performed before primary closure. If the extent of the excision exposes cartilage, the procedure follows dehiscence of the primary repair, or the tissue is not sufficiently healthy, the surgeon should use a posterior auricular flap.

Keywords Fistula / Surgical flap / Sutures
Correspondence: Ho Jik Yang Department of Plastic and Reconstructive Surgery, Eulji University Hospital, Eulji University School of Medicine, 95 Dunsanseo-ro, Seo-gu, Daejeon 302-799, Korea

Tel: +82-42-611-3029

Fax: +82-42-259-1111

E-mail: drhjyang@eulji.ac.kr

Received: 18 Mar 2013 • Revised: 20 May 2013 - Accepted: 23 May 2013

pISSN: 2234-6163・ elSSN: 2234-6171・http://dx.doi.org/10.5999/aps.2014.41.1.45・ Arch Plast Surg 2014;41:45-49

No potential conflict of interest relevant to this article was reported.

\section{INTRODUCTION}

Preauricular abnormalities are believed to result from a failure of fusion of the primitive tubercles from which the pinna is formed. The defects are heritable, are caused by an incompletely dominant autosomal gene, and are common congenital abnormalities in children $[1,2]$. These abnormalities have also been described as preauricular pits, preauricular fistulas, preauricular tracts, and preauricular cysts. Treatment is usually recommend- ed in cases of recurrent infections or bothersome discharge. Various surgical techniques have been described, including simple excision, with or without the use of probes or methylene blue instillation, and a supra-auricular surgical approach [3-5]. In the surgical procedure, total excision of the sinus and fistula is the primary goal [3]. In each case, the extent of the tissue removed is different, and in many cases, the wound cannot be closed by primary suturing because of the extensive excision of the preauricular region. If sutures are used to close the wound despite

Copyright ( $) 2014$ The Korean Society of Plastic and Reconstructive Surgeons

This is an Open Access article distributed under the terms of the Creative Commons Attribution Non-Commercial License (http://creativecommons.org/

licenses/by-nc/3.0/) which permits unrestricted non-commercial use, distribution, and reproduction in any medium, provided the original work is properly cited.

www.e-aps.org 
causing excessive tension, wound dehiscence occurs, contributing to the high ( $5 \%$ to $9 \%$ ) recurrence rates [1]. The purpose of this study was to determine a reconstructive technique that allows for closure of the tissue defect caused by excision of a preauricular sinus.

\section{METHODS}

This study reviewed 28 surgical cases treated between July 2011 and January 2013. In 2 of these cases, fistulectomy had been performed at another hospital and the resultant surgical wound had dehisced before the patients came to this hospital. The other 26 cases involved the first excision of symptomatic congenital preauricular sinuses. The patients' ages ranged from 10 to 35 years, and there were 15 male patients in the group (Table 1).

In each case, the patient was placed under general anesthesia, and an otolaryngologist injected methylene blue dye into the open fistula to determine if the tract was connected to the sinus. Afterwards, the associated structures were totally excised. A plastic surgeon then checked the detached area, measuring the degree of the defect before closing the wound. The closure operations were classified into 3 categories: those involving primary closure only, those involving primary closure with wide undermining, and those involving auricular flap repairs.

\section{Primary closure only}

Primary closure can be easily performed in cases where the preauricular sinus defect is small or the defect is limited to the subcutaneous tissue. In these cases, the surgeon checked that the skin pursed, without a large degree of tension, when the excised tissue was removed. Subsequently, a silicone drain was inserted, without performing a separate procedure. The subcutaneous tissue was repaired using vicryl 5-0 sutures, and the skin was repaired with nylon 6-0 sutures.

\section{Primary closure with wide undermining}

If the resected area was sufficiently large, significant tension could be felt when the surgeon attempted to approximate the wound margins. In these cases, suturing was performed after extensive undermining had been performed (Fig. 1). Undermining was

\begin{tabular}{|ccl|}
\hline \multicolumn{3}{|c|}{ Table 1. Patient characteristics } \\
\hline Patients & Age (yr)/Sex & \multicolumn{1}{c|}{ Closing technique } \\
\hline 1 & $15 / \mathrm{M}$ & Primary closure only \\
2 & $25 / \mathrm{F}$ & Primary closure only \\
3 & $13 / \mathrm{F}$ & Primary repair with wide undermining \\
4 & $19 / \mathrm{F}$ & Primary closure only \\
5 & $22 / \mathrm{M}$ & Primary closure only \\
6 & $29 / \mathrm{F}$ & Primary repair with wide undermining \\
7 & $14 / \mathrm{M}$ & Primary closure only \\
8 & $17 / \mathrm{M}$ & Primary repair with wide undermining \\
9 & $30 / \mathrm{F}$ & Transposition flap \\
10 & $17 / \mathrm{F}$ & Primary closure only \\
11 & $12 / \mathrm{M}$ & Primary closure only \\
12 & $25 / \mathrm{F}$ & Primary repair with wide undermining \\
$13^{\text {a) }}$ & $21 / \mathrm{M}$ & Transposition flap \\
14 & $10 / \mathrm{F}$ & Transposition flap \\
15 & $19 / \mathrm{M}$ & Primary closure only \\
$16^{\text {a) }}$ & $15 / \mathrm{F}$ & Transposition flap \\
17 & $23 / \mathrm{F}$ & Primary closure only \\
18 & $20 / \mathrm{M}$ & Primary closure only \\
19 & $35 / \mathrm{F}$ & Primary repair with wide undermining \\
20 & $27 / \mathrm{F}$ & Primary repair with wide undermining \\
21 & $10 / \mathrm{M}$ & Primary closure only \\
22 & $11 / \mathrm{F}$ & Primary closure only \\
23 & $18 / \mathrm{M}$ & Transposition flap \\
24 & $24 / \mathrm{M}$ & Primary closure only \\
25 & $15 / \mathrm{F}$ & Primary closure only \\
26 & $23 / \mathrm{F}$ & Primary closure only \\
27 & $23 / \mathrm{M}$ & Primary repair with wide undermining \\
28 & $17 / \mathrm{M}$ & Primary closure only \\
\hline a)Re-operations to correct dehiscence after primary repair at another hospital. \\
\hline & & \\
& & \\
\hline & & \\
\hline
\end{tabular}

\section{Fig. 1. A case of wide undermining and primary closure}

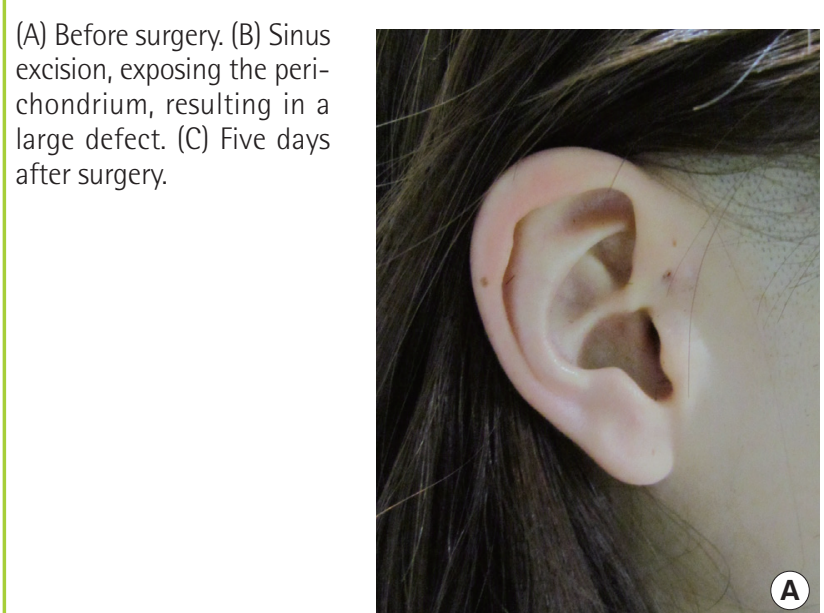

(A) Before surgery. (B) Sinus excision, exposing the perichondrium, resulting in a large defect. (C) Five days after surgery.
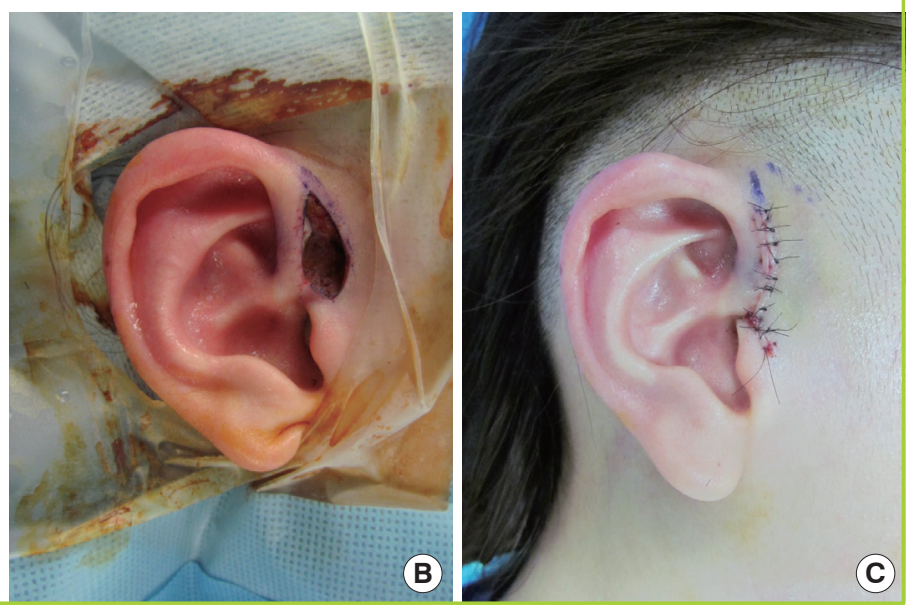
restricted to the depth of the subcutaneous layer. The incision extended upward, $3 \mathrm{~cm}$ above the anterior root of the helix, towards the scalp, and then downward, wrapping around the auricular lobe and descending $3 \mathrm{~cm}$ along the neckline. This incision is similar to a facelift incision. After the undermining, the tension on the lesion was checked before insertion of the silicone drain. The subcutaneous tissue was repaired with Vicryl 5-0 sutures, and the skin was repaired with nylon 6-0 sutures (Fig. 2).

\section{Auricular flap}

If the auricular cartilage was exposed during excision of the preauricular sinus and the tissue defect around the anterior helical root was wide, closure was performed in such a manner that appropriate padding was maintained. In the present cases, tissue reconstruction was performed using an auricular flap. The posterior auricular transposition flap was useful for upper

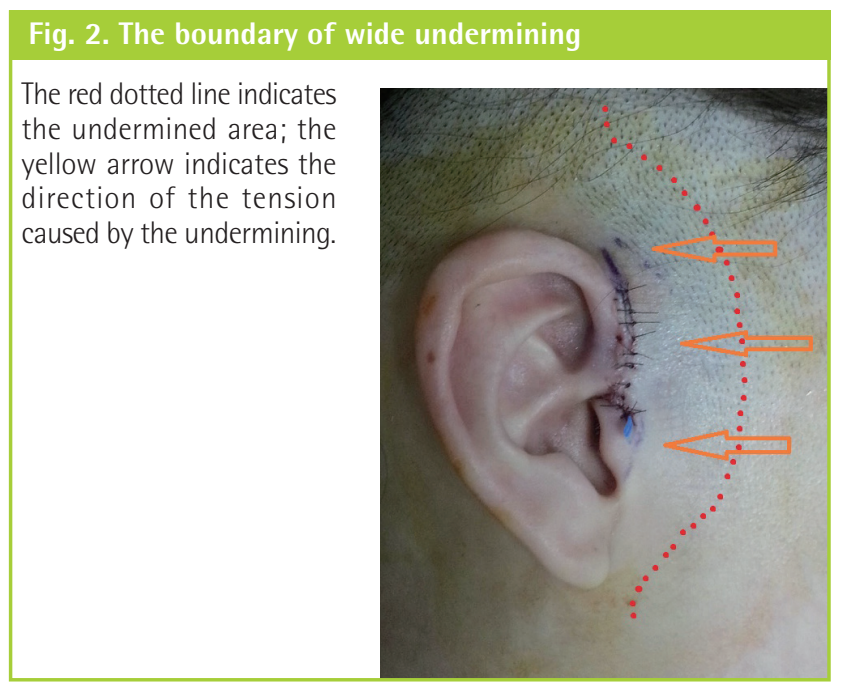

preauricular defects (Fig. 3). An elliptical incision was made at the posterior auricular groove. Then, the flap was placed over the defect and fixed using an upper subcutaneous paddle as a pedicle. The subcutaneous pedicle of the transposition flap was eccentrically located at the proximal end of the elliptical skin paddle; the flap was transferred to the defect by a rotation of up to $120^{\circ}$ on the subcutaneous pedicle. Finally, full-thickness suturing was performed using nylon 6-0 sutures (Fig. 4).

\section{RESULTS}

Of the 28 cases examined, primary closure was performed in 23 cases, and in 5 cases, including the 2 patients admitted following

\section{Fig. 4. Flap design and technique}

(A) The dark area in the preauricular area is the defect, and a transposition flap was designed to reconstruct this area. The blue circle is the basal root of the subcutaneous pedicle. (B) After a successful flap operation. Folding may occur between the flap root and the thin flap; however, a flexible flap that can withstand some folding can be prepared because of the presence of the stable blood supply in the dermis of the posterior auricular area.

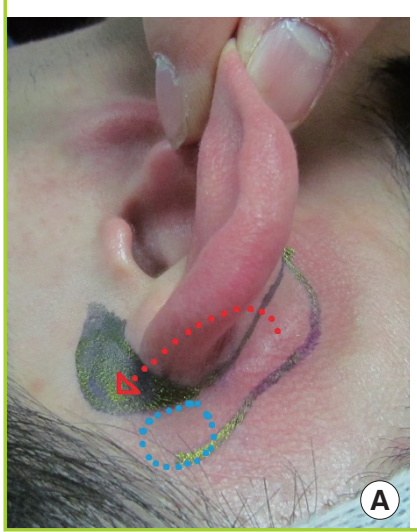

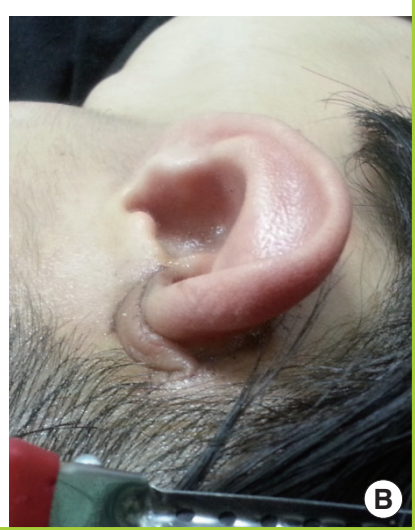

\section{Fig. 3. A case of a posterior auricular transposition flap}

A 21-year-old man experienced wound dehiscence after preauricular sinus excision and primary closure. (A) Before surgery, there was no evidence of healing after 2 months of dressing treatment. (B) A flap elevated at the posterior auricular groove. (C) The flap was placed on the defect at the anterior helical root. (D) After surgery, with the stitches removed.
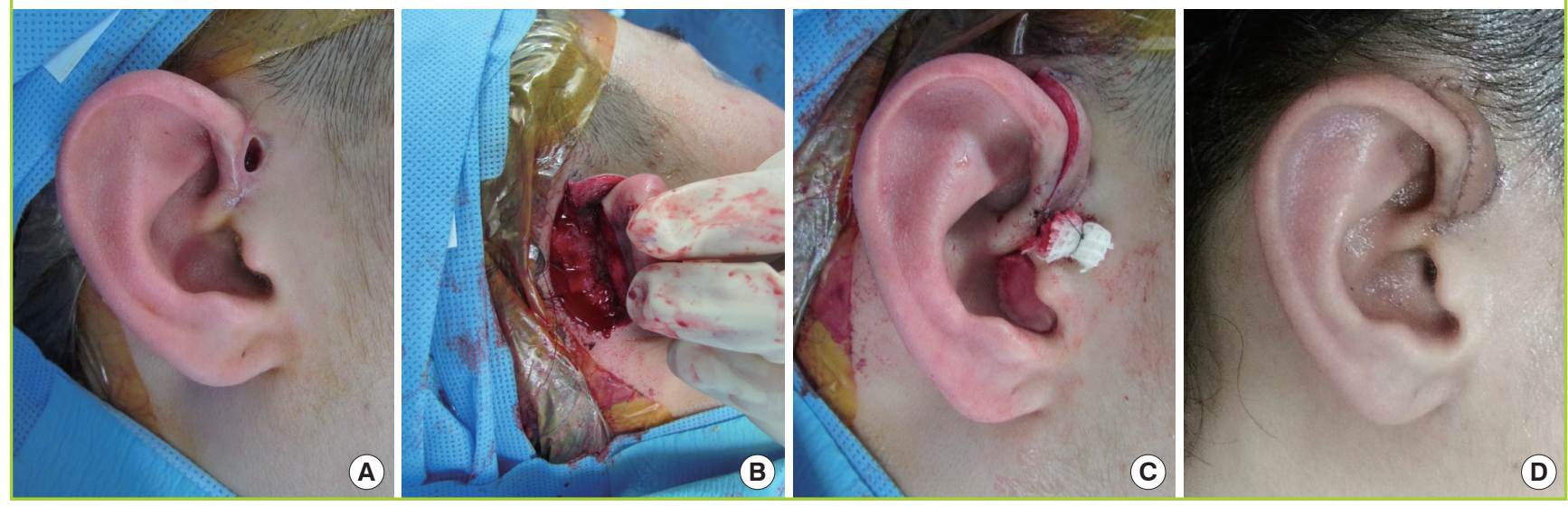


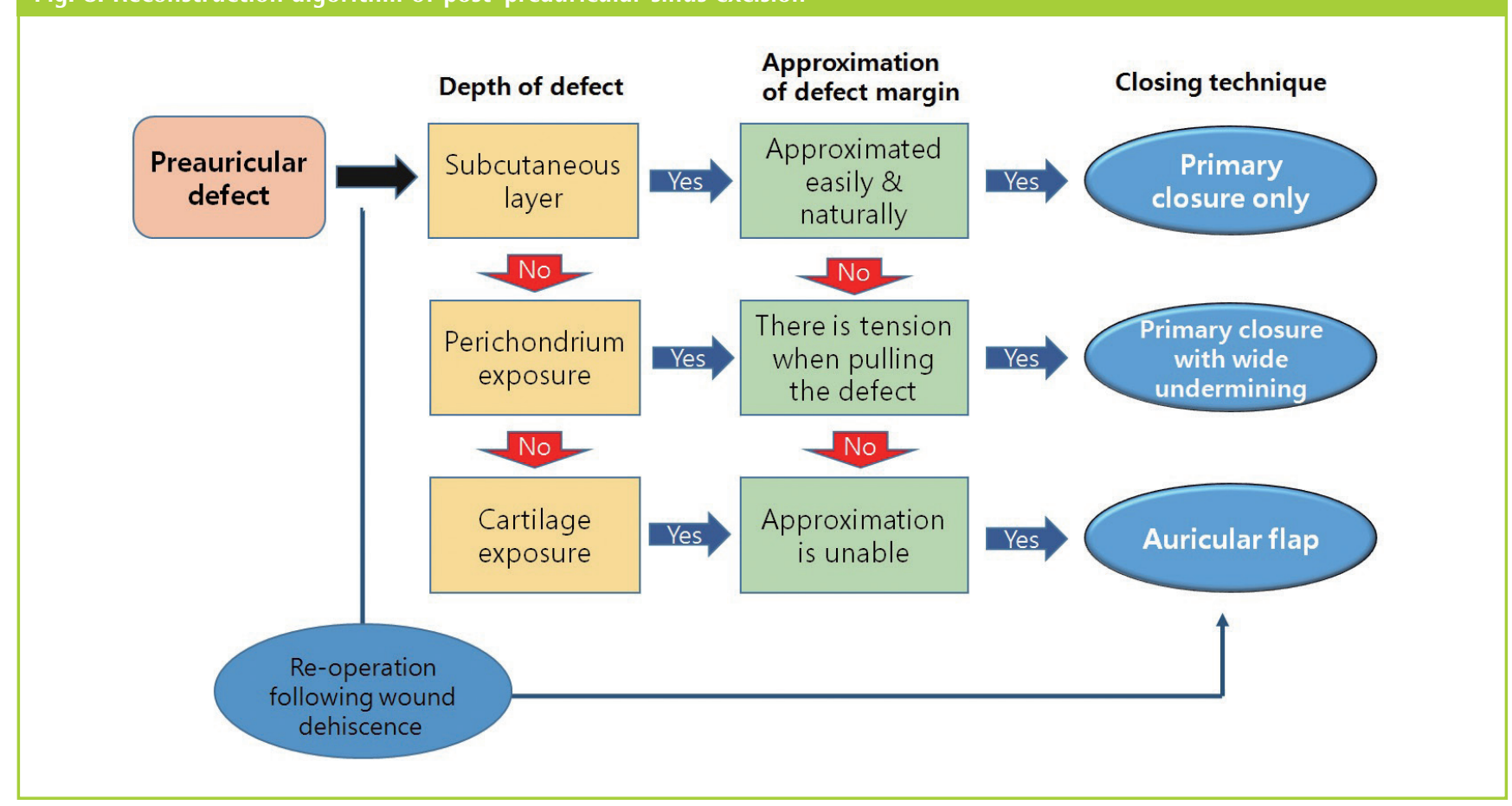

wound dehiscence resulting from previous fistulectomies, reconstruction was performed using an auricular flap. In 16 of the 23 cases involving primary closure, repair was performed using simple suturing; in 7 cases, the repair was performed after suturing that was preceded by wide undermining. Drain removal was performed on the third postsurgical day in each case. The stitches were removed on the sixth postsurgical day in the patients undergoing primary repair and on the tenth postsurgical day in the cases involving a flap repair. Postsurgical wound dehiscence did not occur in any patient. One patient who underwent primary repair and wide undermining experienced some minimal central necrosis, and one patient who underwent flap repair had necrosis of the flap tip. In both cases, a noticeable color change was observed by the second postsurgical day but eventually resolved. Wound revision surgery was not necessary in any patient, but 1 patient, who had undergone simple primary repair, requested scar revision.

Based on a review of this clinical series, a reconstruction algorithm was developed for treating wounds caused by preauricular sinus excision (Fig. 5). If the extent of surgery is small, and the defect is limited to the subcutaneous tissue level, primary repair should be considered. When the auricular perichondrium is exposed or the wound size results in skin tension that does not allow simple suturing, wide undermining should be performed before suturing. Finally, if the auricular cartilage is exposed or there are large tissue defects resulting from excision of the preauricular sinus, a posterior auricular flap should be chosen, based on the position of the defect [6].

\section{DISCUSSION}

A preauricular sinus is a congenital abnormality that has been described in the literature since 1864 [1]. Recently, various surgical methods, including preoperative ultrasonography evaluations, preoperative sonograms, use of a lacrimal probe, and microscopic excisions have been studied as treatment modalities $[7,8]$. However, most surgical methods have focused on the excision itself, with insufficient attention being given to the treatment of the resultant wound.

All defects created after sinus excision are generally closed with simple repair of the old school, and this frequently causes wound dehiscence due to the tension caused by the suture [3]. Hospital stays are longer and the risks of secondary infection are increased when such patients are treated by continued dressing changes and delayed revision surgery. The wound infection may worsen, with the development of chondritis, because the area is adjacent to the cartilage $[3,6]$. This complication can be reduced by determining the best approach to the treatment: simple suture, primary repair with wide undermining, or the use of a posterior auricular flap, depending on the degree of tension and the depth of the defect.

The blood supply to the skin in the posterior auricular area is unusually rich $[9,10]$. This supply is derived from an arterial arcade situated in the auriculocephalic groove between the 
auricular cartilage and the skull, below the auricularis posterior muscle. This arterial arcade is formed by the auricular branch of the posterior auricular artery and the posterior branch of the superficial temporal artery. Therefore, a relatively long, thin flap has been used to cover various auricular area defects in the posterior auricular area $[6,11]$. Although revolving door flaps and twisted skin pedicle flaps are often used, the posterior auricular transposition flap is the most useful, considering that the preauricular sinus usually creates a fistula in front of the helical root. Although a posterior auricular transposition flap should generally be considered, if the defect is in the region of the tragus, a folded de-epithelialized skin pedicle flap should be considered. Additionally, if the defect extends to near the lobe, an inferiorly based transposition flap should be considered.

The sufficient blood supply in the posterior auricular area was divided, starting from the arterial arcades. Because of the development of the subdermal plexus flap, it was possible to create long, thin flaps that made possible a broad range of flap positions. While the flap is being positioned, folding can occur around the proximal end of the skin paddle, which is the pedicle root. However, a small degree of folding is not problematic because of the stable circulation and flexible posterior auricular flap. During surgery, the surgeon should scrape the flap margin and check the margin bleeding to evaluate the circulation status. Because subcutaneous repair may disrupt the circulation, the surgeon should perform full-thickness suturing with nylon sutures to approximate the alignment of the margins. Furthermore, the donor site in the posterior auricular area should be sutured before suturing the flap and defect area. Circulation disorders may be discovered by checking the flap margins for bleeding immediately after closing the donor site.

The reconstruction technique suggested in this paper has the advantage of being applicable to various excision methods, and should be considered when repeat surgery is necessary. This is especially true when postsurgical wound dehiscence becomes chronic and a flap of healthy tissue is required to cover the scar [9]. Furthermore, because the posterior auricular area has a rich vascular supply, flaps from this area adhere well to other tissue, leading to higher success rates [12]. In this study, 2 cases involved postsurgical wound dehiscence in which the tissue defects had become chronic, without any improvement being seen over a 2-month period. The posterior auricular transposition flap was used to successfully treat these cases, and patient satisfaction was high.

Scars in the preauricular area may be thought to be more bearable because they are covered by long hair [3]. However, if the patient has short hair or is young, the surgeon should try to minimize the size of the scar. Therefore, primary repair after wide undermining was chosen over closure with a local flap. This obviated the need for an additional skin incision to decrease skin tension when approximating the margins of the wound, resulting in more aesthetic outcomes.

\section{REFERENCES}

1. Tan T, Constantinides H, Mitchell TE. The preauricular sinus: a review of its aetiology, clinical presentation and management. Int J Pediatr Otorhinolaryngol 2005;69:1469-74.

2. Thorne CH, Brecht LE, Bradley JP, et al. Auricular reconstruction: indications for autogenous and prosthetic techniques. Plast Reconstr Surg 2001;107:1241-52.

3. Gan EC, Anicete R, Tan HK, et al. Preauricular sinuses in the pediatric population: techniques and recurrence rates. Int J Pediatr Otorhinolaryngol 2013;77:372-8.

4. Baatenburg de Jong RJ. A new surgical technique for treatment of preauricular sinus. Surgery 2005; 137:567-70.

5. Bae SC, Yun SH, Park KH, et al. Preauricular sinus: advantage of the drainless minimal supra-auricular approach. Am J Otolaryngol 2012;33:427-31.

6. Schonauer F, Vuppalapati G, Marlino S, et al. Versatility of the posterior auricular flap in partial ear reconstruction. Plast Reconstr Surg 2010;126:1213-21.

7. Lam HC, Soo G, Wormald PJ, et al. Excision of the preauricular sinus: a comparison of two surgical techniques. Laryngoscope 2001;111:317-9.

8. Kumar KK, Narayanamurthy VB, Sumathi V, et al. Preauricular sinus: operating microscope improves outcome. Indian J Otolaryngol Head Neck Surg 2006;58:6-8.

9. Yoshimura K, Nakatsuka T, Ichioka S, et al. One-stage reconstruction of an upper part defect of the auricle. Aesthetic Plast Surg 1998;22:352-5.

10. Yanai A, Okabe K, Nakamura Y. Epidermal cyst originating from the preauricular sinus. Plast Reconstr Surg 1987;79: 265-6.

11. Chang YL, Chen YR, Noordhoff MS. Reconstruction of middle-third auricular defect based on aesthetic perception theory. Aesthetic Plast Surg 1990;14:223-5.

12. Choi JH, Kim JY, Yoo YS, et al. Chondrocutaneous advancement flap for helical rim defect. Korean J OtorhinolaryngolHead Neck Surg 2010;53:252-5. 